\title{
The Promotion Background of Qi-qi Cotton Textile Machine
}

\author{
Wen Zhang ${ }^{1} \&$ Xiaoming Yang ${ }^{1}$ \\ ${ }^{1}$ College of Humanities, Donghua University, Songjiang, Shanghai, China \\ Correspondence: Xiaoming Yang, College of Humanities, Donghua University, Songjiang, Shanghai, 201620, \\ China. E-mail: ynide@sina.com
}

Received: October 17, 2019

Accepted: October 24, 2019

Online Published: November 19, 2019

doi:10.5539/ass.v15n12p68

URL: https://doi.org/10.5539/ass.v15n12p68

Foundation item: The year 2018-2019 Fundamental Research Funds for the Central Universities and Graduate Student Innovation Fund of Donghua University "Research on the development of sizing technology in China " (Project No., CUSF-DH-D-2019105) stage of achievements.

\begin{abstract}
The Qi-qi cotton textile machine of 1977 is a handmade textile machine which was vigorously promoted by the government in the 1930s in China. Its name comes from the Chinese homonym of the July 7 th Incident. This paper discusses the reasons and process of popularization of the Qi-qi cotton textile machine by the Agricultural Production Committee under the special background of the Anti-Japanese War. Through the deep analysis of historical data, this paper summarizes the Popularization Background and reasons of the machine. It is believed that the Qi-qi cotton textile machine increased the domestic cotton yarn output, largely met the cotton yarn demand in the southwest and northwest of China at that time, increased the income of the residents in the popularization area, and filled the cotton textile demand in the period of the Anti-Japanese.
\end{abstract}

Keywords: Qi-qi cotton textile machine, promotion background

The impact of the world financial crisis has led major powers to intensify the plunder of colonies. Modern China, as a semi-colonial and semi-feudal country, struggled to advance in an environment surrounded by powerful enemies. After Japan's full-scale invasion of China began in 1937, all walks of life in China suffered a strong blow, especially the destruction of the new cotton textile industry and cotton textile handicraft industry. Food and clothing is not only the main artery of the national economy, but also the main supply of the army. If we want to devote ourselves to a comprehensive and long-term war of resistance, we must first have adequate food and clothing. Although the new cotton textile industry has been developed during the First World War, its development is still far from enough: "Check the original spindles in our country, only more than 3 million. If we want to provide clothing for our compatriots, we must increase it to more than 10 million ingots. But after the Japanese invaded China in an all-round way, there were only 500,000 ingots left (Mu, 1921)." In order to meet the needs of the people and the army, Lu Shaoyun pointed out that small-scale yarn mills should be built ( $\mathrm{Lu}$, 1929), while Mu Louchu suggested vigorously promoting the development of cotton textile handicraft industry (Mu, 1939).

\section{Advantages of Developing Cotton Textile Handicraft Industry}

In view of the current situation, the implementation of cotton textile handicraft industry has the following advantages compared with the construction of small-scale yarn mills:

First, cotton textile handicraft industry is more suitable for promotion in areas with abundant cotton output and abundant labor force. During the Anti-Japanese War, China had a large quantity of cotton and it was cheap. Japanese also valued China as an important cotton producing area, and set up many yarn factories in Qingdao. Compared with machine spinning, manual spinning occupied more manpower, spent more time and cost; however, the quality of spinning yarn was uneven, so the price of manual spinning at that time was lower than that of factory yarn. Therefore, if you want to make a profit by hand spinning, you need the raw material price to be low enough, that is, cotton price to be low enough. China's cotton production is large and its labor force is abundant, which fits the two major conditions for the cotton textile handicraft industry to make profits.

Secondly, the cotton textile handicraft industry has low requirements for machines, does not need too many steel 
parts, is easy to assemble, and the raw materials for manufacturing hand-made cotton spinning machines are cheap and easy to obtain. Although it is hand-spun, it still needs some tools. Wood is the main material for cotton textile handicraft industry. It is cheaper and easier to obtain than iron and other metals. Only by keeping the wood dry and measuring accurately, qualified instruments can be produced. The machine structure required by small cotton textile mills is more complex, the cost of raw materials is high, and because of the power reasons, the energy requirements are very strict, which is not conducive to promotion $(\mathrm{Mu}, 1939)$.

Thirdly, the requirements for organization and management of cotton textile handicraft industry are lower than those of large cotton textile mills. Most of the areas where cotton textile handicraft industry is carried out are located in rural areas, and the quality of personnel is different, which can not meet the requirements of personnel management of large-scale cotton textile mills. Comparatively speaking, only about 20 people are needed in the cotton textile handicraft industry. The quality of personnel is low and easy to manage. As long as appropriate wages are formulated, the management of personnel can be adjusted properly by means of wages. According to Mu Louchu's calculation, according to the prices at that time, every worker needed to earn about three salaries a day to survive, so the necessary wages were very necessary.

Fourth, in the establishment of cooperative organizations, the implementation of cotton textile handicraft industry is more convenient than the development of small-scale cotton yarn mills. Good cooperative organizations can share risks. Small-scale yarn mills are relatively independent, and it is difficult to form cooperatives (Zheng, 1939).

Fifth, the Committee for Agricultural Extension strongly supports the development of cotton textile handicraft industry. Because $\mathrm{Mu}$ Lou was a member of the Agricultural Extension Committee at the beginning, the promotion of cotton textile handicraft industry is smaller than that of large-scale yarn mills. The Committee for Agricultural Extension also has an organ for financial business. Besides general commercial banks, it also deals with special business. There are six organizations below:

1. Business Section. The following sections include the Treasury and Warehouse Operations Sections.

2. Agricultural Adjustment Department. It consists of production section and purchasing and selling section.

3. Secretaries and accountants.

4. Research room.

5. Cooperative guidance room. There are six lakes, Guangxi, Sichuan, Shaanxi and Guizhou.

Most of the organs with which they cooperate are local cooperative Treasuries and cooperatives, which ensure the adequacy of funds.

These are the advantages of developing cotton textile handicraft industry in the special period of the Anti-Japanese War over Establishing small-scale yarn mills.

\section{Selection of Machine Types in Promoting Handmade Cotton Textile Industry}

\subsection{Comparison of Foreign Machines and Domestic Yarn Machines}

At that time, the Agricultural Promotion Committee could choose among three small cotton textile machines. They are Indian-style cotton textile machine, German-style cotton textile machine and China's own homespun yarn machine. Among them, the Indian textile machine is simple, with a total of 168 spindles. It can spin twenty yarns and sixty-five pounds per hour. The total value of the machine is about 12,000 rupees (Mu, 1938). Amway sells the machine. The German cotton textile machine is simple, and its effectiveness is equal to that of the Indian cotton spinning machine. The number and price of the machines are unknown (Mu, 1939). However, because the two kinds of yarns are produced abroad, with high cost, complex structure and multi-purpose steel, they are not suitable for popularization and use in the period of the Anti-Japanese War in China, so it is imperative to use our own native yarn machine.

\subsection{Contrast of Several Kinds of Domestic Self-owned Earth Yarn Machines}

1) Trinity. The Trinity model, advocated by Chen Quzhen, has 16 lead tubes and a yarn rolling car on the machine. It cost about 30 to 50 yuan when it was first introduced. After the beginning of the Anti-Japanese War, prices rose and construction costs rose. However, due to its "novel structure and practical application", the Ministry of Economic Affairs has granted new patents for five years" (Yang, 1941) and there are patent problems, so it is difficult to popularize them in large areas.

2) Liangzi period. There are fifty lead tubes. However, the use of iron in beam stage is more and the cost is higher.It is worth mentioning that the handmade cotton textile machine used by Zhu Ziqiao in the orphanage in 
Shaanxi Province is just like this. But it has more iron parts and higher cost, which is more suitable for small factories. However, the Liangzi period cotton textile machine at that time "wanted to patent this machine", so the possibility of promotion was greatly reduced $(\mathrm{Mu}, 1941)$.

3) Industry-intensive. Advocated by Wang Ruiji and Liu Zhijun, the cost of 50 lead pipes was as high as 200 yuan in the Republic of China in 28 years, and it rose further after the war. The industrial refined cotton textile machine is transformed from Liangzi period type, and there are also some patent problems.

4) Qi-qi cotton spinning machine, formerly known as "army", was introduced to Sichuan in the late Qing Dynasty. Zizhou was its birthplace (Liu, 1939). It was improved by Mu Lotus Root. Mu Louchu was a chairman of the Agricultural Promotion Committee of the Kuomintang Government during the War of Resistance Against Japan and a founder of the Sichuan Cotton Textile Promotion Committee. In May 1936, Mu Lou Chu collected various kinds of cotton textile machines in Hankou for research, and then selected ten of them which were suitable for agricultural extension, sent two of them to Shanxi, two to Hunan, and the remaining six to Sichuan for further research; but later, after arriving in Chongqing, a cotton spinning native to Sichuan was discovered. In addition to a small number of looms, the six cotton textile machines brought about by comparison are more perfect nowadays, so decided to improve the local cotton textile machine in Sichuan, and named the improved cotton textile machine "Qi-qi cotton textile machine" (Liu, 1939).

During the Anti-Japanese War, in order to ensure the output of cotton textile products, Mu Lou Chu improved the seven-seven cotton spinning machine, and vigorously promoted in Sichuan, Shu, Hunan and Hubei.

\section{Workflow and Matters Needing Attention of Qiqi Cotton Textile Machine}

\subsection{Workflow of Qiqi Cotton Textile Machine}

\section{1) Cotton Picking}

The cotton seeds, debris, leaves, etc. in cotton are sorted out, and then the cotton is beaten heavily with a three-foot long thin bamboo pole.

Then you can use the elastic cotton machine.

\section{2) Shell-cotton}

Spread the cotton on the cover of the cotton spreader. Push the cotton into the gap by hand. The person standing behind the machine can start to tread on the pedal. Standing in front of the machine, people should constantly push cotton into the machine mouth, pedal frequency should be appropriate, and then according to experience to determine the speed of pedal. If the pedal suddenly becomes heavier, it is necessary to stop in time and take out the stuck cotton before proceeding to the next step.

\section{3) Cotton sliver}

Spread the elastic cotton layer by layer on the cotton reel board to the appropriate thickness, and then roll the cotton on the cotton reel from the side of the cotton with the cotton reel rod, so as to ensure that the subsequent sliver can be removed smoothly from the cotton reel rod.

\section{4) Cotton Sliver Loading}

The unloaded sliver is clamped in the bamboo insert, the bamboo insert is fed into the lead tube tube of the spinning machine, and then the bamboo insert is pulled out, so the sliver loaded into the tube is left in the tube.

\section{5) Spinning}

Insert the tube with cotton sliver into the circular hole in the small groove disc on the frame of the spinning machine, then place the yarn head of the yarn winded on the top of the frame in the tube, and then hang it with the sliver fibers in the tube. At this time, step on the pedal, make the coiled wooden disc start to rotate, and the yarn head that has been rolled will drive the fibers in the tube. Rotate to the winding tray, while the lead tube is also rotating. The sliver fibers in the tube are yarned by the rotation of the lead tube, so that continuous yarn can be obtained. Attention should be paid to the situation of broken ends and yarn head coarsening. Hand-twisting can be used to ensure the reconnection of yarns according to the initial method.

6) Rolling Yarn

The coiled wooden tray full of yarn can be removed and replaced with another empty one. Removal of the wooden tray, you can put on the yarn spinning machine, will find the yarn head, the yarn head tied to the frame, and then hand-yarn, tied down, set on the horn of the bandage sheep, it becomes a skein. This kind of skein can be directly made into warp yarn after sizing and can also be shaken into weft yarn (Liu, 1939). 


\subsection{Matters Needing Attention in the Use of Qi-qi Cotton Textile Machine}

1) When spinning, we must pay attention to the rope. Spinning rope should pay attention to the consistency of tightness, too loose will lead to rope tray speed is too slow, too tight will lead to pedal too tight, trampling will be more laborious. Maybe it's the best way to improve an inch by three or four points.

2) The cotton rope of the Qi-qi textile machine can be made of the yarn that the mechanic spins himself. If the yarn can be made of 745 yarns, sixty yarns are suitable. The most important thing is that the yarn must be rubbed tightly enough.

3) Before spinning every day, lubricating oil should be added to the rotating part of the spinning machine, which can not only save stamping strength, but also prolong the life of the spinning machine. If impurity ash is found in the rotating part, it should be wiped out in time.

4.) When the sliver is loaded into the lead drum, it is necessary to observe whether the wire under the lead drum is straight or not. If the wire is not straight, it should be straightened in time, otherwise the spinning quality will be affected by the inflexibility of the top and bottom rotation of the lead drum.

5) The hanging distance of the hanging hammer can affect the yarn size. To increase roving, the hanging distance of the hanging hammer can be shortened, and the hanging distance of the hanging hammer can be lengthened if the yarn is thinned. The suspension distance of the hanging hammer should be observed at any time to ensure the evenness of yarn thickness (Mu, 1938).

6) If there are stiff cotton blocks or cotton chips sticking to the yarn during the spinning process, the yarn can be cleaned only by removing them.

7) Probe into the causes of yarn breakage: If there is yarn breakage, it is necessary to observe whether the yarn is too thin due to the hanging distance of the hanging hammer, or whether the yarn is unevenly slender due to the uneven treading force.

Generally speaking, China has its own native yarn machine, which can be divided into three routes according to its development route, one way is from the Yangtze River to the west of Henan Province to Shaanxi, one way is along the Yangtze River to Sichuan, and the other way is through the Yangtze River to Hunan. However, in comparison, the cost and output of the spinning machine is more suitable for China during the Anti-Japanese War (Mu, 1941). Therefore, the Agricultural Extension Committee decided to promote the Qi-qi cotton textile machine, hoping to fill the domestic military and civil needs for cotton yarn.

\section{Reasons for the Successful Implementation of Qi-qi Cotton Textile Industry}

1. During the Anti-Japanese War, the promotion of various undertakings was closely related to transportation. Many work was delayed due to the inconvenience of transportation during the war. However, the seven-seven cotton textile machine adopted a polygonal mode of implementation at the beginning, not focusing on a single point, but opened textile training centers in several provinces at the same time. The Training Institute has trained a large number of technicians and students, most of whom have learned to use the seven-seven cotton textile machine, indirectly making the number of seven-seven cotton textile machine has also increased considerably.

2. Agricultural Promotion Committee has a remarkable effect on the training institute. For the difficulties of the training institute, the Agricultural Promotion Committee either gives funds, dispatches personnel, or subsidizes machinery, which has made great progress in training and guaranteed the development of cotton textiles.

3. The textile structure of Qi-qi cotton is relatively simple, the material is mostly bamboo and wood, and the requirement of copper and iron components is very little. The craftsmen in different places can make it by themselves. Even if the structure of the more complex elastic cotton machine, the Agricultural Promotion Committee will mail to difficult areas, so that the popularization of the seven-seven cotton textile machine has been guaranteed.

4. When Mu Lou-chu improved the textile of Qi-qi cotton, he took the enthusiasm of large-scale production and drew in detail the machine pattern of Qi-qi cotton textile machine. "Printing thousands of copies, sending them out to all parties, facilitating imitation" (Mu, 1938).

5. The Committee on Agricultural Extension has given a great deal of help to the newly established handicraft textile factories and training institutes in various regions to reduce the foreseeable difficulties.

6. Wartime yarn prices soared. During the printing of the relevant books of the 1977 cotton textile machine in the Republic of China, the yarn price was about 4,500 yuan per package. By 1941, the price was "ten times higher than before". The high price drove people to engage in the manual textile industry, which promoted the 
popularization of the 1977 cotton textile industry.

\section{Disadvantage and Countermeasure of Qi-qi Cotton Textile Machine in Promotion Period}

1. There are some deficiencies in training cadres and personnel. Since the promotion of Qiqi cotton textile machine, a large number of trainees and technicians have been trained, but due to the lack of manpower of the promotion committee, it has not been able to give full play to its advantages. In the process of promotion, there is no well-defined goal, resulting in no better promotion effect.

2. The establishment of machinery factories is still inadequate. In May 1941, about 1,000 skilled technicians of the Qiqi cotton textile machine trained in Chengdu were unemployed for lack of machinery, and their survival was very problematic. To solve this problem, Zheng Zhongyao proposed that Sichuan should be divided into four regions: western Sichuan, northern Sichuan, Eastern Sichuan and southern Sichuan. Machinery factories should be set up in each region to ensure the supply of machinery (Ge, 1941).

3. For textile students who have learned how to spin by hand but are unable to buy machines, Zheng Zhongyao proposes to implement the method of sending flowers and receiving yarns on loan machines. Lending machines to the right mechanics and allowing them to return the corresponding loans within the prescribed time can not only help the country's production, but also meet the needs of personal life. The work of hairdressing and yarn harvesting can be undertaken by the Agricultural Extension Committee. This measure can reduce hoarding and manipulate prices, so that the wartime market is macroscopically manipulated by the government and concentrates on the War of Resistance. Stabilizing prices can also reduce the consumption of cotton purchased in rural areas, but also improve production efficiency. After hearing the suggestions, the Agricultural Extension Committee implemented the policy of hairdressing and yarn harvesting in northern Sichuan. At the same time, after taking over the Agricultural Products Adjustment Office, the Agricultural Extension Committee has also set up "Fushengzhuang" to deal with the acquisition of agricultural products, adjust supply and demand, and strive to achieve the goal of "making the best use of everything" (Mu, 1941).

\section{References}

Ge, M. S. (1941). A review of the promotion methods of Qi-qi cotton spinning machine. Agricultural Base, 54, 5-50.

Liu, Z. R. (1939). Qi-qi cotton spinning machine usage. Construction Week, 9, 21-26.

Lu, S. Y. (1939). How to build China's textile industry during the Anti Japanese War. Textile Dyeing Engineering, 3, 1-11.

$\mathrm{Mu}$, L. C. (1921). The development history of Chinese cotton industry. Shanghai Chamber of Commerce monthly, 5, 209-218.

Mu, L. C. (1938). The past and future of China's cotton textile industry. Cooperative monthly, 14, 6-14.

Mu, L. C. (1939). Solve the problem of cotton spinning. Textile Dyeing Engineering, 3, 12-15.

$\mathrm{Mu}, \mathrm{L}$. C. (1941). My opinion on the implementation of earth yarn machine and hand spinning. Agricultural Base, 48, 5-13.

$\mathrm{Mu}, \mathrm{L}$. C. (1941). The promotion of 77 cotton spinning machine in the past three years. Agricultural Extension Communication, 7, 3-6.

Yang, Y. L. (1941). Chen Quzhen invents Quanzhen spinning machine. Southwest Industrial Communication, 3, 40-41.

Zheng, Z. Y. (1941). The prospect of hand spinning in the future. Agricultural Base, 54, 7-13.

\section{Copyrights}

Copyright for this article is retained by the author(s), with first publication rights granted to the journal.

This is an open-access article distributed under the terms and conditions of the Creative Commons Attribution license (http://creativecommons.org/licenses/by/4.0/). 